\title{
The Validity of Setting a Benchmark Standard Based on Academic Fields in the Indirect-Student Survey for Quality Assurance in Japan
}

\author{
${ }^{1}$ Yamazaki Shinichi, ${ }^{2}$ Miyazato Shota \\ ${ }^{1}$ J.F. Oberlin University, Japan \\ ${ }^{2}$ Graduate School of J.F. Oberlin University, Japan
}

\begin{abstract}
This article examines the validity of setting a benchmark standard based on academic fields at the national level indirect-student survey for quality assurance in Japanese junior colleges. The data derives from The National Survey for Junior College Students (NSJCS), called as "Tandaiseichosa" in Japanese. The NSJCS is one of the leading indirect student surveys in junior colleges operated by the Japanese Association for College Accreditation (JACA), which is a certified accreditation agency for junior colleges. Research method applies a comparative study of the results of single tabulations and a correlation analysis on junior college student experiences and their learning outcomes by applying 58,119 data in three academic fields, Childhood Education, Multi-disciplinary, and Health Science, from NSJCS 2015-2018. As a result of this empirical study, benchmark standards of each academic field contribute to improving the quality assurance system of Japanese junior colleges by clarifying characteristics of educational experiences and learning outcomes. Each academic fields have a way of acquiring learning outcomes in their educational experiences, and these outcomes varied from not only each institution but also the academic field.
\end{abstract}

\section{Introduction}

The purpose of this research is to clarify the importance of creating a benchmark standard based on academic fields in "Tandaiseichosa", which is a National Survey for Junior College Students (NSJCS) and one of the leading national-level indirect student surveys to Japanese junior college students. This survey aims to contribute to improving educational quality and accountability to the general public as a part of the processes of accreditation. Japanese Association for College Accreditation (JACA) is one of the certified accreditation agencies in Japan. It operates a college evaluation to support continuous self-study and assessment of member institutions for sustaining and improving the quality of education and research activities in junior college as a quality assurance system. It becomes a sister organization with the Accreditation Commission for
Community and Junior Colleges (ACCJC), which is a part of the Western Association of Schools and Colleges (WASC) in the U.S [1]. Institutional certified evaluation and accreditation mandates to all Japanese colleges and universities at least once of every seven years by the School Education Act in 2004. JACA is one of them, and the number of member institutions of JACA is 276 (84\% of junior colleges). As a part of accreditation procedures, JACA applies NSJCS based on a spontaneous request from junior colleges. The NSJCS consists of questionnaires of reasons for enrollment, educational experiences, study-hours, learning outcomes, and satisfaction to correspond to the context of Japanese junior colleges by entirely relying on indirect-student evaluation.

JACA research committee framework has been enabling the periodical and continuous improvement of NSJCS through analyzing the data from the survey. This committee is organized less than 20 professionals such as researchers of learning outcome assessment, administrators of higher education institutions, and the principle of kindergarten. Research \& development still underway after JACA commercialized the survey in 2017 despite R\&D tends to be completed with operationalized in Japanese education research generally. This unique committee contributes to sustaining and refines NSJCS to adapt to changing social demands to the learning outcomes assessment. The authors of this paper are a member of a research and analysis team in this committee. Therefore, this research identifies the validity of comparison by academic fields to promote the educational quality and accountability of Japanese junior colleges through improving quality assurance system.

\section{Background}

The environment surrounding higher education institutions in Japan is becoming increasingly severe due to a variety of factors, including intensifying competition due to a declining 18-year-old population, globalization, and a reduction in current subsidies. The shrinking of the college-age group is one of the most significant issues to manage every 
Japanese higher education institution sustainable because they hugely rely on younger students in their enrollment management. The Ministry of Education, Culture, Sports, Science and Technology (MEXT) shows that only about 3,000 students are over 25 years old among 631,273 attendees to universities while the situation of junior college is almost the same, less than 3\% adult students [2]. The reason for the low numbers of adult students in Japanese higher education institutions is that business companies tend not to offer recurrent education to their employees because these enterprises prepare On the Job Training (OJT) programs to them. The Ministry of Health, Labour and Welfare (MHLW) explains that only $1.8 \%$ of companies apply job training opportunities in higher education institutions [3]. Despite the low demand for job training to employees, Japanese companies strongly expect graduates from higher education institutions to respond shrinking of the working-age population and insufficient human resources.

The School Education Act prescribes junior college, the main research objective of this paper, as "aiming to develop knowledge, morals, and applied abilities by teaching and studying specialized fields for cultivating essential abilities and basic skills for working industrial society and living life well". Thus, junior colleges focus on acquiring fundamental skills and abilities while university aims to give extensive knowledge to students as the academic center. The demographics of Japanese junior colleges have a unique characteristic. Female students dominate $88.7 \%$ of total enrollment in 2018 because the beginning of this kind of institution aims to expand access to higher education for women to foster the social promotion of them from 1950. However, the number of junior colleges and its enrollment has continued to decline significantly due to the growing social orientation to university-level education, and women's empowerment. The number of students in junior colleges as of 2019 is 113,008, which is less than a quarter of peak term in the end [2].

Japanese national educational policy tries to sustain junior college despite the shrinking of its size. One of the working groups in the Central Council for Education, which affects educational policymaking under the MEXT, proposes a report to making the solution for Mid- to long-term issues around junior colleges. This report expresses the four fundamental roles of junior colleges in the future Japanese society as (1) a place to development of professional workers, (2) cultivating key persons to contribute to the local community, (3) to be a firststage of higher education level before attaining 4years university, and (4) provide various opportunities to the life-long learning [4].

Japanese junior colleges still have more than 100,000 students, even in the situation of a declining birthrate and growing the trend toward a four-year university. One of the reasons that they are mainly composed of fields with substantial needs for human resources, such as kindergarten teachers and nursery teachers, as well as nurses and caregivers, and play a role in developing human resources in a short period and sending them to society. For example, almost half of junior college student studies in early childhood education for becoming a kindergarten/ nursery teacher to support primary education. These facts examine that the role of junior colleges in Japanese higher education is still crucial despite a reduction.

Furthermore, in the global perspectives, shortcycle higher education institutions are one of the trends in the rest of developed countries to expanding access to the tertiary level of education even though the number of Japanese junior colleges is shrinking. Thus, this paper focuses on the utilization possibility of the indirect-student survey to apply the quality assurance system in Japanese junior colleges as a case of one of the short-cycle higher education issues.

\section{Previous research}

The prototype of NSJCS, called as Japanese Junior College Student Survey (JJCSS), developed in 2008 to correspond to the demand of learning outcome assessment of higher education institutions by the Japanese Cooperative Institutional Research Program (JCIRP). This project deserved to create one of the trends of learning outcome assessment through the indirect-student survey in Japanese higher education institutions. Yamada [5], the leader of JCIRP, shows that an indirect-student survey derives educational impacts and learning outcomes of colleges and universities from comparisons of the Japanese College Student Survey (JCSS) and College Senior Survey (CSS). CSS is conducted by the Higher Education Research Institute at University California Los Angeles and to be an example for JJCSS with permission. Yamada [6] also clarifies the possibilities and challenges of a large scale continuous student survey through analyzing the JJCSS data and shows that the impact of satisfaction of college experiences causes from personal factors rather than college factors themselves. JJCSS turned into NSJCS in 2015 to focus on Japanese junior college characteristics; 2 years basis, small size, and 18-19 years old female dominant enrollment, to improve the educational quality of Japanese junior colleges and improve accountability to stakeholders through the indirectstudent evaluation [7].

The trend of learning outcomes assessment in junior colleges spread to regional level practice such as a Junior Colleges Consortium Kyushu (JCCK). Kyushu is one of the regions in Japan and JCCK 
attempts an original approach to quality assurance in these member institutions. Abe and Nanri [8] explain that JCCK aims to clarify and strengthen the roles and functions of junior colleges that are closely connected to the community and contribute to the development of mid-level human resources in the community. One of the characteristics of the efforts from JCCK combine an indirect student survey with a panel survey to their graduate to measure educational outcomes of these institutions organizes as their quality assurance system.

\section{Objective and method}

Improving accountability and measuring the learning outcomes in higher education institutions is one of the central issues all over the world. There are many kinds of surveys to students besides the trends of evidence-based / qualitative research such as the NSJCS. The results of this indirect-student survey have already had utilized not only the quality assurance of junior colleges but also academic research. Okamura [9] focuses that the student's characteristics of laboratory technician course while Miyazato [10] explains student's attitudes toward college education evaluation, and awareness in child food education courses in their junior colleges based on the results from the survey. Yamazaki [11] explains the differences in learning practice in junior college and university's students by comparing study hours between them using the NSJCS data and another national survey. However, there is no research work related to cross-disciplinary comparisons of NSJCS data according to the CiNii, which is the most extensive bibliographic database service of academic resources in Japan.

This paper aims to identify the importance of the benchmark standard based on the academic field through a comparative study of learning experiences and outcomes in each field by applying the data of NSJCS 2015-2018, almost 20,000 junior college students participate in every year. The research focuses on three academic fields in NSJCS, Childhood Education (CE, the total number of respondents is 31,792), Multi-disciplinary (MD, 8,464 in total) such as cultural studies and interdisciplinary fields, and Health Science (HS, 17,863 in total), those fields are major factors of Japanese junior colleges. This paper applies to compare the results of single tabulations and correlation analysis on junior college student experiences and their learning outcomes in these three academic fields.

\section{Results}

Figure 1 shows the frequency of learning experience in the class of junior college in each academic field (Fig. 1).

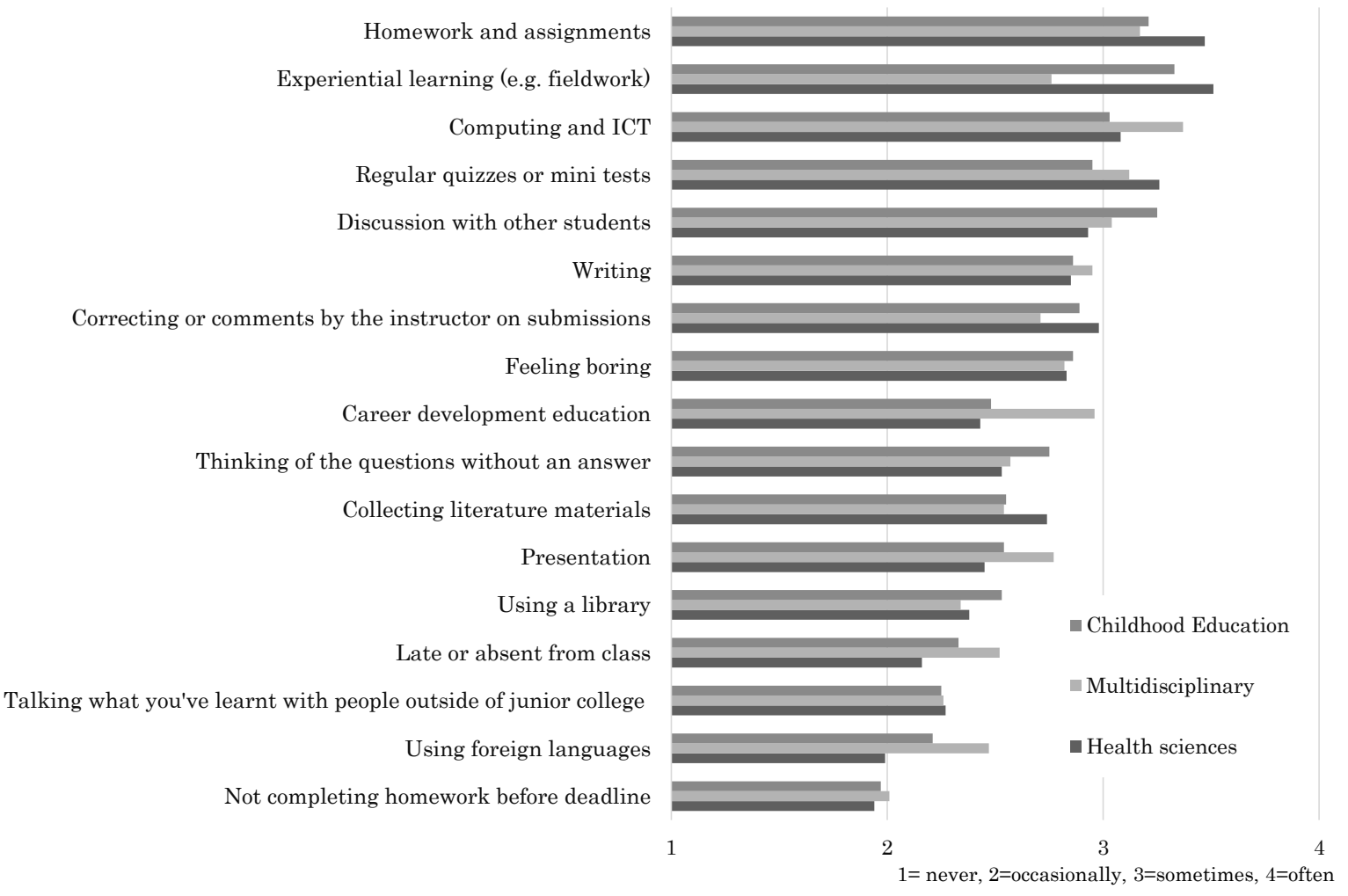

Figure 1. The frequency of learning experiences in junior college 
Table 1. Characteristic of educational experiences in each field

\begin{tabular}{c|lc|ll}
\multicolumn{1}{c}{ Positive } & \multicolumn{2}{c}{$\begin{array}{c}\text { Key factor } \\
\text { Major fields }\end{array}$} & \multicolumn{1}{c}{ Negative } \\
\hline \hline Childhood & Discussion with other students & 3.25 & Computing and ICT & score \\
Education & Thinking of the questions without an answer & 2.75 & Regular quizzes or mini tests \\
(CE) & Using a library & 2.53 & & \\
\hline & Career development education & 2.96 & Experiential learning (e.g. fieldwork) \\
Multi- & Using foreign languages & 2.47 & Correcting or comments by the instructor on submissions & 2.76 \\
Disciplinary & Writing & 2.95 & Late or absent from class \\
(MD) & Computing and ICT & 3.37 & \\
& Presentation & 2.77 & \\
\hline & Experiential learning (e.g. fieldwork) & 3.51 & Discussion with other students \\
Health & Regular quizzes or mini tests & 3.26 & Presentation & 2.52 \\
Sciences & Homework and assignments & 3.47 & Career development education \\
(HS) & Correcting or comments by the instructor on submissions & 2.98 & Using foreign languages \\
& Collecting literature materials & 2.74 & \\
& Late or absent from class & 2.16 &
\end{tabular}

Questions related to the learning experiences consist of 17 questions with a four-point scale, "Homework and assignments", "Experiential learning (e.g., fieldwork)", "Computing and ICT", "Regular quizzes or mini-tests", "Discussion with other students" and others. These items intend to identify the frequency of each educational experience and to assess educational activities in junior colleges. Negative educational experiences like "Late or absent from class", "Not completing homework before the deadline", and "Feeling boring", are inversion items. Students in all three academic fields have many opportunities to take homework, using a computer, mini-tests, and discussion as to their learning experiences, and they can be considered earnest by the low rate of the "Not completing homework before the deadline".

Table 1 examines the character of educational experiences in each field. These positive/negative vital factors choose at least \pm 0.3 scores between 3 academic fields. Childhood Education tends to apply "Discussion with other students", "Thinking of the questions without an answer", and "Using a library" while it does not focus on "Computing and ICT" and "Regular quizzes or mini-tests" comparing by other 2 fields. Most of the students in CE pursue to be a kindergarten/nursery teacher as a professional job. MEXT and MHLW propose that active learning like "Discussion with other students" and "Thinking of the questions without an answer" is to be one of the essential factors to improve childhood education.

The Multi-Disciplinary field provides a variety of educational experiences, and that does not focus on professional works. Some junior colleges intend on international understanding while others allow their students to think about their career and future works. "Late or absent from class" as a negative factor is a little bit higher than the other two fields. Students in the Multi-Disciplinary tend to struggle to keep their motivation for studying due to the unclear purpose and target of their study program.

HS fields prepare educational curriculum to their students for attaining the position of nutritionist, nurse, caregiver, medical technician, and other professional works related to health services. These kinds of professions require the license for working authorized by the national law, so students force to achieve the standard of each profession. Therefore HS students spend "Experiential learning (e.g., fieldwork)" as a part of job training and "Regular quizzes or mini-tests", "Homework and assignments", to pass the examination to be qualified as a profession. "Late or absent from class" is lower than other fields because the MHLW operates the attendance of class strictly to be a nutritionist as one of the examples. These students are not able to have enough opportunities to take time for discussion and presentation while pursuing the license and qualification to be a profession.

Figure 2 shows what kind of skills or abilities acquiring as a learning outcome from junior college experiences. This questionnaire consists five-point scale, significantly decreased, decreased, nothing change, increased, and increased greatly.

"Knowledge in specialized fields" is the only item to exceed 4 points, which points out all fields of junior college students obtain skills and knowledge related to their field. "Teamwork and collaboration skills", "Writing skills", "General knowledge", "Communication skills", and "Computer skills" follows in this figure. The purpose of junior college in the School Education Law declares that studying specialized fields for cultivating essential abilities and necessary skills for working industrial society and living life well and the survey result show attaining some level of this requirement as a junior college.

On the other hand, some crucial abilities like "Leadership skills" and "Understanding numerical values and data" are not acquired well through their educational experiences. CE and HS suffer from even decreasing "Foreign language proficiency" while MD sustains the level of it. These students do not tend to have an opportunity to learn a foreign language because there is enough space in their curriculum only in 2-years.

Table 2 suggests that characteristics of learning outcomes comparing three academic fields. These questionnaire items tend to stay high every year with stably since the beginning of NSJCS, therefore, these 


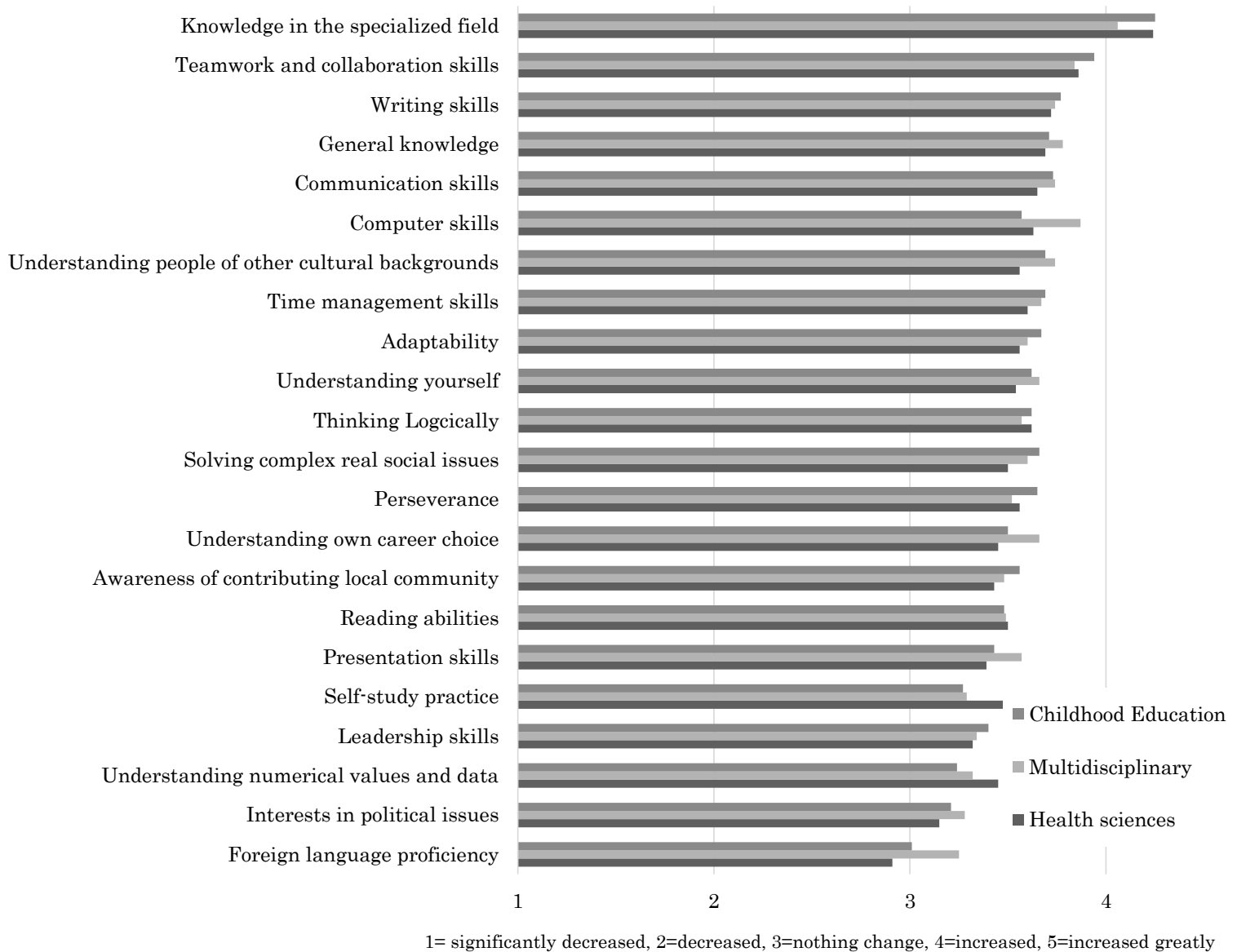

Figure 2. Increase/decrease of skills and abilities as learning outcomes in junior college

Table 2. Characteristic of learning outcomes in each field

\begin{tabular}{|c|c|c|c|c|}
\hline \multirow[b]{2}{*}{ Major fields } & \multirow[b]{2}{*}{ Positive } & \multicolumn{2}{|c|}{ Key factor } & \multirow[b]{2}{*}{ score } \\
\hline & & score & Negative & \\
\hline \multirow{5}{*}{$\begin{array}{l}\text { Childhood } \\
\text { Education } \\
\text { (CE) }\end{array}$} & Knowledge in the specialized field & 4.25 & Computer skills & 3.57 \\
\hline & Teamwork and collaboration skills & 3.94 & \multirow{4}{*}{ Understanding numerical values and data } & \multirow[t]{4}{*}{3.24} \\
\hline & Adaptability & 3.67 & & \\
\hline & Perseverance & 3.65 & & \\
\hline & Awareness of contributing local community & 3.56 & & \\
\hline \multirow{6}{*}{$\begin{array}{c}\text { Multi- } \\
\text { Disciplinary } \\
\text { (MD) }\end{array}$} & Computer skills & 3.87 & \multirow[t]{6}{*}{ Knowledge in the specialized field } & \multirow[t]{6}{*}{4.06} \\
\hline & General knowledge & 3.78 & & \\
\hline & Understanding people of other cultural backgrounds & 3.74 & & \\
\hline & Understanding own career choice & 3.66 & & \\
\hline & Presentation skills & 3.57 & & \\
\hline & Foreign language proficiency & 3.25 & & \\
\hline Health & Knowledge in the specialized field & 4.24 & Communication skills & 3.65 \\
\hline \multirow{2}{*}{$\begin{array}{c}\text { Sciences } \\
\text { (HS) }\end{array}$} & Self-study practice & 3.51 & \multirow{2}{*}{ Understanding yourself } & \multirow[t]{2}{*}{3.54} \\
\hline & Understanding numerical values and data & 3.45 & & \\
\hline
\end{tabular}

positive and negative factors pick up \pm 0.1 scores in their comparison.

$\mathrm{CE}$ contributes to acquiring essential abilities such as "Teamwork and collaboration skills", "Adaptability", "Perseverance", and "Awareness of contributing local community" with "Knowledge in the specialized filed" to be a profession of childhood education. The field of early childhood education tends to lag behind digitalization as suggesting key negative factors.
Students in MD supposed to have a varied range of skills and abilities through their own educational experiences. It shows different from 2 other specified fields while taking the lowest score of "Knowledge in specialized fields".

Key factors such as "Knowledge in specialized fields", "Self-study practice", of HS point out the apparent tendency of its learning outcomes. HS students require to pass the examination to attain the profession. Furthermore, nutritionist and other 
Table 3. Correlation analysis between leaning outcomes and learning experiences

\begin{tabular}{|c|c|c|c|c|c|c|c|c|c|c|}
\hline$\underbrace{\substack{\text { Leaning } \\
\text { Outcomes }}}_{\substack{\text { Leaning } \\
\text { Experiences }}}$ & $\begin{array}{c}\text { Making } \\
\text { Presentation }\end{array}$ & $\begin{array}{c}\text { Discussion } \\
\text { with other } \\
\text { students }\end{array}$ & $\begin{array}{l}\text { Collecting } \\
\text { literature } \\
\text { materials }\end{array}$ & Using a library & \begin{tabular}{|c|} 
Experiential \\
learning \\
(e.g. fieldwork)
\end{tabular} & $\begin{array}{c}\text { Career } \\
\text { develoment } \\
\text { education }\end{array}$ & \begin{tabular}{|c|} 
Thinking of the \\
questions \\
without an \\
answer
\end{tabular} & $\begin{array}{l}\text { Writing and } \\
\text { sentence } \\
\text { expression }\end{array}$ & $\begin{array}{l}\text { Computing } \\
\text { and ICT }\end{array}$ & $\begin{array}{l}\text { Using forieng } \\
\text { languages }\end{array}$ \\
\hline $\begin{array}{l}\text { Knowledge in the } \\
\text { specialized field }\end{array}$ & & $\mathrm{CE}^{*}$ & & & $\mathrm{CE}^{\star} / \mathrm{HS}^{*}$ & & & & & \\
\hline Thinking Logcically & & $\mathrm{HS}^{*}$ & $\mathrm{HS}^{*}$ & & & & $\mathrm{CE}^{\star} / \mathrm{MD}^{\star} / \mathrm{HS}^{*}$ & & & \\
\hline $\begin{array}{c}\text { Understanding people of } \\
\text { other cultural } \\
\text { backgrounds }\end{array}$ & & $\mathrm{HS}^{*}$ & & & & & $\mathrm{MD}^{*}$ & & & $\mathrm{MD}^{*}$ \\
\hline $\begin{array}{l}\text { Teamwork and } \\
\text { collaboration skills }\end{array}$ & & $\mathrm{CE}^{\star}$ & & & & & & $\mathrm{HS}^{*}$ & & \\
\hline $\begin{array}{l}\text { Solving complex real } \\
\text { social issues }\end{array}$ & & $\mathrm{HS}^{*}$ & & & & & $\mathrm{CE}^{*} / \mathrm{MD}^{*} / \mathrm{HS}^{*}$ & & & \\
\hline Writing skills & & & $\mathrm{MD}^{*}$ & & & & $\mathrm{MD}^{*}$ & $\mathrm{CE}^{*} / \mathrm{HS}^{*}$ & $\mathrm{HS}^{*}$ & \\
\hline Reading abilities & & & $\mathrm{CE}^{*} / \mathrm{MD}^{*} / \mathrm{HS}^{*}$ & $\mathrm{MD}^{*} / \mathrm{HS}^{*}$ & & & $\mathrm{MD}^{*}$ & $\mathrm{CE}^{*} / \mathrm{HS}^{*}$ & & \\
\hline $\begin{array}{l}\text { Understanding numerical } \\
\text { values and data }\end{array}$ & & & $\mathrm{HS}^{*}$ & & & & & HS & & \\
\hline $\begin{array}{l}\text { Foreign language } \\
\text { proficiency }\end{array}$ & & & & & & & & & & $\mathrm{CE}^{*} / \mathrm{MD}^{\star \star} / \mathrm{HS}$ \\
\hline Communication skills & $\mathrm{MD}^{*}$ & $\mathrm{MD}^{*}$ & & & & & & & & \\
\hline Presentation skills & $\mathrm{CE}^{\star} / \mathrm{MD}^{\star \star} / \mathrm{HS}^{*}$ & $\mathrm{CE}^{\star} / \mathrm{MD}^{*} / \mathrm{HS}^{*}$ & & & & & $\mathrm{MD}^{*}$ & & & \\
\hline Computer skills & & & & & & & & $\mathrm{HS}^{*}$ & $\mathrm{CE}^{\star /} / \mathrm{MD}^{\star} / \mathrm{HS}^{*}$ & \\
\hline $\begin{array}{l}\text { Understanding own } \\
\text { career choice }\end{array}$ & & & & & & $\mathrm{MD}^{*}$ & & & & \\
\hline
\end{tabular}

Note:
All of the correlated items show at significant level $1 \%$

1) All of the correlated items show at significant level $1 \%$

2) $\mathrm{CE}=$ Childhood Education, $\mathrm{MD}=$ Multi-Disciplinary, $\mathrm{HS}=$ Health $\mathrm{Sciences}$
${ }^{*}$ weak correlation $(\mathrm{r}=0.2 \sim 0.4)$, ** positive correlation $(\mathrm{r}=0.4 \sim 0.7),{ }^{* * *}$ strong correlation $(\mathrm{r}=0.7 \sim 1.0)$, n.s. = Blank cell

3) *weak correlation $(\mathrm{r}=0.2 \sim 0.4)$, ** positive corre
4) Decorrelation items are hidden on this table.

professions need to understand numerical values and data as a part of works. To concentrate passing examination, "Communication skills" and "Understanding yourself" tend to not increase in their learning outcomes.

As in the final section of the results of this paper, table 3 suggests the correlation coefficient between learning outcomes and experiences in junior colleges based on three major fields, CE, MD, and HS. The table is an attempt to perform a correlation analysis on question items related to learning outcomes and learning experiences. There is a weak correlation between "Presentation skills" and educational experiences of "Making presentation" and "Discussion with other students", "Reading abilities" and "Collecting literature materials", abilities of "Thinking logically" and "Solving complex real social issues" from "Thinking of the questions without answers". "Computer skills" and "Computing and ICT", "Foreign language proficiency", and "Using a foreign language" also correlate at a weak level in all fields. "Presentation skills" and "foreign language proficiency" correlate positively in each related experience in the MultiDisciplinary field. There is no item confirming a strong correlation with this analysis.
CE students tend to acquire "Knowledge in the specialized field" and "Teamwork and collaboration skills" from discussion with other students as showing the correlation. "Experiential learning (e.g., fieldwork)" also correlates with "Knowledge in the specialized field" while "Writing and sentence expression" experiences deserve to acquire "Writing skills" and "Reading abilities".

"Thinking of the questions without answer" makes a positive effect on the outcomes of "Understanding people of other cultural backgrounds", "Writing skills", "Reading abilities", and "Presentation skills" in the field of MultiDisciplinary. "Understanding own career choice" as learning outcome only correlates with "Career development education" experience due to some junior colleges have an educational curriculum relates to career development as an entry-level program to industrial society after graduation.

Discussion experiences in HS students affect to have abilities of "Thinking logically", "Understanding people of other cultural backgrounds", and "Solving complex real social issues" even though their amount of experience of "Discussing with other students" tends to be lower compared to other academic fields. "Writing and sentence expression" has a positive impact on not 
only "Writing skills" but also "Reading abilities", "Teamwork and collaboration skills", "Understanding numerical values and data", and "Computer skills". "Computing and ICT" experience is also a correlation with "Writing skills" in HS.

The results of correlation analyses confirm that the tendency of acquisition of learning outcomes differs from depending on each field even in through similar learning experiences. Japanese quality assurance system supposes to have problems that it does not require distinct academic majors in their evaluation processes. Their scope to evaluate an educational program is too whole. It needs to shift to sectoral assessment based on the characteristics of each academic major to improve educational quality and accountability to the general public in each junior college.

\section{Conclusion}

This comparative study in Japanese junior college data figures out the characteristics of the learning experiences in each academic field and different learning outcomes might occur even by the same learning experiences between EC, MD, and HS through comparison of single aggregate results and correlation analysis on NSJCS data. This result finds that analyzing the academic sector basis and making a benchmark standard based on each academic field is an essential factor in understanding the educational aspects in each junior college. These institutions can have an opportunity to compare themselves more precisely by the academic field's benchmark to support self-evaluation as a part of the quality assurance system.

This result suggests the importance of analyzing each academic major to improve the quality of educational assessment in junior colleges. On the other hand, this study also supposes the limitation of the indirect-student survey to apply the evaluation processes of higher education institutions. Educational activities consist of many factors such as faculty, an instructor, a student, atmosphere of the classroom, course setting in the curriculum, and even personal matter of student. There is also a huge possibility to manage classes in different approaches, even in the same class name. These factors may affect the answers from junior college students in NSJCS.

Therefore, the NSJCS, one of the indirect student survey, make clear learning experiences and its outcomes broadly as well as obscuring detail perspectives of learning activities in junior colleges. Educational assessment requires to have multiple approaches, quantitative and qualitative ways to improve the quality assurance system for enriching the educational quality and accountability to the general public for obtaining public support to higher education institutions.

\section{References}

[1] Japan Association for College Accreditation. 'Historical Overview' http://www.jaca.or.jp/en/about/histry.html (10 January 2020).

[2] Ministry of Education, Culture, Sports, Science and Technology. (2019) 'School Basic Survey', Education Policy Bureau.

[3] Ministry of Health, Labour and Welfare. (2019) 'Basic Survey of Human Resources Development', Human Resource Development Bureau.

[4] Central Council for Education. (2014) 'About the Future of Junior Colleges' [Translated from Japanese]. Working Group of Junior College.

[5] Yamada, R. (2008) 'Affective fulfillment and learning outcomes of college students: analysis of CSS and JCSS'. Research in Higher Education vol. 40, pp. 183-198.

[6] Yamada, R. (2010) 'the possibility and challenges of a large scale continuous student survey system: through analysis of JCIRP data'. Research in Higher Education vol.42, pp. $247-263$.

[7] Yamazaki, S. and Sakai, O. (2016) 'Development of new junior college student survey following the JJCSS' In R. Yamada (Eds.) The quality of higher education and its evaluation [Translated from Japanese.]. Tokyo: Toshindo, pp.131-144.

[8] Abe, E. and Nanri, Y. (2018) 'New horizon of junior college education’ Tokyo: Hokuju Publisher.

[9] Okamura, M. (2017) 'the characteristics of medical technician course considering through Tandaiseichosa' [Translated from Japanese]. Bulletin of Sanyo Women's College vol.38, pp.49-58.

[10] Miyazato, S. (2019), 'Student's Evaluation and Consciousness to Pre-school Teacher Education/Training Experiences in Junior college', Journal of Higher Education Administration vol.9, pp.79-93.

[11] Yamazaki, S. (2018) 'Current status and issues of study time in junior college and university students', Psychological and Educational Research vol.9, pp.43-50.

\section{Acknowledgements}

This work was supported by Japan Society for the Promotion of Science (JSPS) KAKENHI Grant Number JP18K1394. 